\title{
Results of an Intro to Mechanics Course Designed to Support Student Success in Physics I and Foundational Engineering Courses
}

\section{Prof. Gustavo B Menezes, California State University, Los Angeles}

Menezes is a Professor of Civil Engineering at Cal State LA. His specialization is in Environmental and Water Resources Engineering. Since becoming part of the faculty in 2009, Menezes has also focused on improving student success and has led a number of engineering education projects. He is currently the Director of the First-Year Experience program at ECST (FYrE@ECST) and coordinates engineering education activities at the college of engineering, computer science and technology (ECST).

\section{Prof. Paul S Nerenberg, California State University, Los Angeles}

Dr. Paul S. Nerenberg is currently an Assistant Professor of Physics and Biology at California State University, Los Angeles. He received his PhD in Physics from MIT and has a strong interest in improving the quality of introductory physics education, particularly for students who enter college with little or no previous physics coursework.

\section{Ni Li, Northwestern Polytechnial University}

Ni Li, Ph.D., was an Assistant Professor of the Department of Mechanical Engineering at California State University, Los Angeles. Now, she is working in the school of Aeronautics at Northwestern Polytechnical University as a professor. She earned her BS in Electrical Engineering from Northwestern Polytechnical University, Xi' an, China, and her MS in Electrical Engineering, MS in Aerospace Engineering, and $\mathrm{PhD}$ in Mechanical Engineering from University of Central Florida. She previously served as a lecturer at University of Central Florida.

\section{Dr. Emily L. Allen, California State University, Los Angeles}

Emily L. Allen, Ph.D., is Dean of the College of Engineering, Computer Science, and Technology at California State University, Los Angeles. She believes in a collaborative, student-centered approach to research, education, academic administration and leadership. She currently chairs the ASEE Engineering Deans Council Diversity Committee, and serves on the ABET Academic Affairs Council, the TMS Accreditation Committee, and the National Board of Directors for the Society of Hispanic Professional Engineers. Dr. Allen earned her BS in metallurgy and materials science from Columbia University, and her MS and $\mathrm{PhD}$ in materials science and engineering from Stanford University. She previously served as faculty, chair and Associate Dean at San Jose State University's College of Engineering. 


\section{Results of an Introduction to Mechanics Course Designed to Support Student Success in Physics I and Foundational Engineering Courses}

This complete evidence-based practice paper discusses the strategies and results of an introduction to mechanics course, designed to prepare students for introductory-level physics and other fundamental courses in engineering, such as statics, strength of materials, and dynamics. The course was developed to address historically high failure (DFW) rates in the physics courses and is part of a set of interventions implemented to support student success in a college of engineering and computer science. The course focuses on providing in-depth understanding of Newton's Laws of motion, free-body diagrams, and linear and projectile motion. Because it focuses on a limited number of competencies, it is possible to spend more time on inquiry-based activities and in-class discussions. The course framework was designed considering the Ebbinghaus' Forgetting Curve, to provide students with learning opportunities in 6-day cycles: (i) day 1: a pre-class learning activity (reading or video) and a quiz; (ii) day 2: in-class Kahoot low-stakes quiz with discussion, a short lecture with embedded time for problem-solving and discussion, and in-class activities (labs, group projects); (iii) day 4: homework due two days after the class; (iv) day 6: homework self-reflection (autopsy based on provided solutions) two days after homework is due. The assessment of course performance is based on the wellcharacterized force concept inventory (FCI) exam that is administered before the intro to mechanics course and both before and after the Physics I course; and on student performance (grades) in Physics and Statics courses. Results from the FCI pre-test show that students who took the introduction to mechanics course (treatment group) started the physics course with a much better understanding of force concepts than other students in the course. The FCI post-test shows better normalized gain for the treatment group, compared to other students, which is also aligned with student performance in the course. Additionally, student performance is significantly better in statics, with $25 \%$ DWF rate compared to $50 \%$ for the other students. In summary, the framework of the course, which focuses on providing students with in-depth understanding of force concepts, has led to better learning and performance in Physics I, but importantly it has also helped students achieve better performance in the Statics course, the first fundamental course in civil and mechanical engineering programs.

\section{Institutional Background}

California State University, Los Angeles (Cal State LA), one of 23 campuses of the California State University (CSU) system, was ranked number one in the U.S. for the upward mobility of its students, according to The Equality of Opportunity Project (2017) [11], and the College of Engineering, Computer Science, and Technology (ECST) serves as a valuable gateway for youth from minority groups in East Los Angeles to enter STEM careers. In Fall 2018, the College of ECST had 3093 undergraduate students, with 62.3\% Hispanic, 15.4\% Asian and Pacific islanders, 5.3\% White, 2.5\% African-American, 10.2\% International (mainly undocumented California residents), and $4.3 \%$ others. ECST has the highest percentage of Hispanic students among all engineering colleges within the California State University system. In addition, 60\% of ECST students are first-generation college students; 70\% are maximum Pell grant eligible, 
and nearly all students are commuters. While most of our incoming students are passionate about attaining success and giving back to their families and communities, they also encounter significant learning barriers in achieving their academic goals. Currently, the 4-year, 5-year and 6-year graduation rates for our freshman students are 3.6\%, 22.7\% and 38.7\% respectively, which are not only way below the national average, but also lower than many sister colleges in the CSU system. Significant institutional attention is focused on improving these graduation rates, while remaining an access institution in terms of admission.

\section{FYrE Program Introduction and the Need for Introduction to Mechanics Course}

Five years ago, the College of Engineering, Computer Science, and Technology (ECST) piloted the First-Year Experience (FYrE@ECST) ${ }^{[1],[2]}$ program, which included supplemental instruction $^{[3]}$ workshops for Calculus I, II, and Physics I - (Mechanics) courses, block scheduling in cohorts, holistic advising ${ }^{[4]}$ with focus on academics and career preparation, and a new project-based Introduction to Engineering and Technology course for a pilot cohort of 30 engineering students. The program was initially funded through an institutional grant provided by the Helmsley Foundation and more recently by $\mathrm{NSF}^{[5]}$. During the past five years, the research team tested a number of interventions, of which some were more effective than others. For the current $\left(5^{\text {th }}\right)$ cohort, FYrE also includes computer science students, supplemental instruction workshops for chemistry, peer mentors, and an Introduction to Mechanics course. The Introduction to Mechanics course (ENGR1540) is a preparatory course for the traditional Physics I - (Mechanics), and is designed to help students succeed in physics. The course was introduced because, unlike for calculus, student performance in physics showed no significant improvement for FYrE students participating in the supplemental instruction (SI) workshops.

\section{Introduction to Mechanics Course Features}

The Introduction to Mechanics course ${ }^{[6]}$ (ENGR 1540) was introduced in the Fall 2017 semester with focus on providing students with in-depth understanding of fundamental physics concepts, such as Newton's Laws of motion, free-body diagrams, and linear and projectile motion. The course uses active learning strategies such as Kahoot ${ }^{[7]}$, think-pair-share, experiments (e.g. force table, slow motion recording of falling object). In its latest iteration, Fall 2019, the course was redesigned using activities inspired by the Ebbinghaus' Forgetting Curve ${ }^{[8]}$, shown in Figure 1. According to Ebbinghaus' research, a person remembers only $60 \%$ of the material 20 minutes after it has been learned. After 1 day, less than $40 \%$ of the information is retained. At the same time, according to Ebbinghaus' study, which was validated by Murre and Dros ${ }^{[9]}$ in 2015 , if the information is revisited 3 times, after 20 minutes, after a day and within 7 days, $90 \%$ of the knowledge is retained 3 months later. Based on that, ENGR 1540 was designed to be taught on a "6-day cycle" learning strategy to maximize students' learning performance. As illustrated in Figure 2, this learning strategy is composed of pre-class learning, in-class learning, after-class practice, and self-reflection. Classroom setup consists of 6 tables with 4 to 5 students each, which facilitates active learning and student collaboration. 


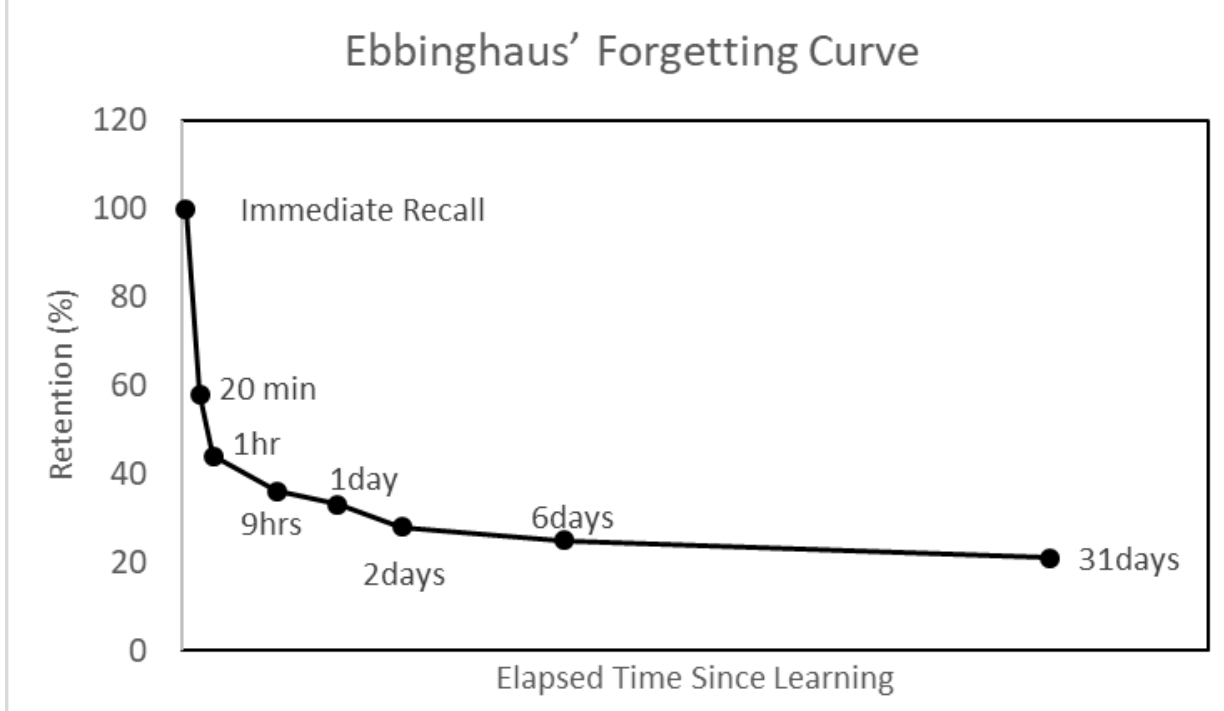

Figure 1. Ebbinghaus' forgetting curve

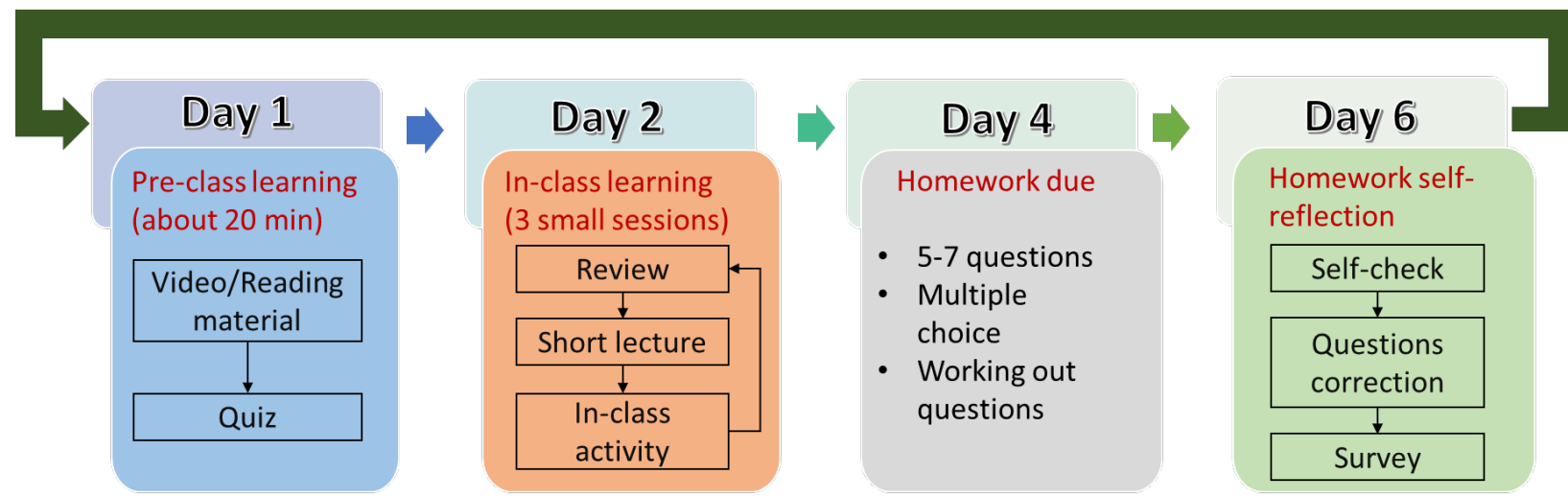

Figure 2. Repetition strategy

ENGR1540 meets once a week in a 2.5 hour class session. The complete 6-day learning cycle is explained as follows:

- Day 1 - Pre-class learning: The goal of the pre-class learning is to let the students achieve simple-level learning objectives defined by the bottom level of Bloom's Taxonomy ${ }^{[10]}$. Students are expected to memorize and be able to define the basic concepts required for ENGR 1540, such as the types of forces, definition of displacement, velocity, and acceleration. A typical Pre-class learning assignment includes watching a video or reading a short paragraph and answering 3-5 multiple-choice questions quizzes. Both video watching and question answering are assigned online through the campus LMS (Canvas). These assignments are required to be finished one day before the face-to-face lectures.

- Day 2 - In-class learning: The 2.5-hour meeting period each week is used to help students achieve learning objectives defined in the $2^{\text {nd }}$ level of Bloom's Taxonomy, developing an indepth understanding of the concepts and principles required in ENGR 1540, including 
Newton's Laws, types of forces, vectors, free-body diagrams, and position, velocity and acceleration.

At the beginning of each class, the instructor spends 5 minutes to address students' questions about the pre-class quiz, and another 5 minutes to check students' understanding of pre-class knowledge using Kahoot ${ }^{[7]}$ games. The questions in the Kahoot games are specially designed based on common mistakes or misconceptions observed from pre-class quizzes. The teaching strategy used in the lecture is inquiry-based learning, and the teaching process is guided using specially designed, logically connected questions to strengthen students' ability for critical thinking. Video demonstrations of real-world applications are used to raise students' interest and keep their attention throughout the class. The 2.5-hour class is always divided into two sessions. In the first part (60 minutes), a quick review of the previous topic is presented and the new topic is delivered through a short lecture. Inquiry-based teaching takes place by providing students with a number of questions and opportunities to think-pair-share. In the second part, students work in group activities to enhance their understanding. These activities usually include problem solving, reflections or experiments, such as the bathroom weight scale experiment - designed for students to master balance of forces and Newton's laws; force table experiment - designed for students to master balance of forces, force vector and component; and ball falling experiment - designed for students to master knowledge of position, velocity, acceleration and Newton's Laws.

- Day 4 - Homework : Homework is assigned after each class and due within 2 days for students to review the course material. Each homework includes 5-7 problems, often geared towards conceptual understanding and explanation of physical phenomena.

- Day 6 - Homework self-reflection: A homework autopsy method ${ }^{[11]}$ is used in ENGR 1540 to help students identify the mistakes in their homework. In the homework autopsy students are provided with a list of common mistakes, which are based on instructors' cumulative experience in teaching the same course. Students are required to first check the homework and correct all the mistakes based on the solutions provided by the instructor and choose the causes of the mistakes listed in the homework autopsy or indicate a different reason. The instructor quickly scans students' feedback before each class and discusses common mistakes in class.

The entire 6-day cycle is repeated 12 times throughout the semester.

\section{Course Assessment}

To assess the effectiveness of ENGR 1540 in enhancing student success in the first semester required General Physics (Mechanics) course (PHYS 2100), we examined three metrics: course grades for PHYS 2100, and pre- and post-course scores on the Force Concept Inventory (FCI) exam $^{[12]}$. To further assess the effectiveness of ENGR 1540 in enhancing understanding of statics concepts, we examined grades in the required Statics course (CE/ME 2010), for which PHYS 2100 is a pre-requisite and a foundation course in Civil and Mechanical Engineering. While course grades are straightforward to understand, they are also subject to considerable variability from institution to institution and - as we will show in results below - year to year 
and instructor to instructor. The FCI exam, an assessment instrument first developed in the 1990 s and widely used in the physics education research community today ${ }^{[13]}$, provides a complementary method for assessing students' understanding that enables more robust comparisons across years (and institutions). The FCI and PHYS 2100 comparisons included $\mathrm{CE} / \mathrm{ME} / \mathrm{EE} / \mathrm{CS}$ students who were part of the intervention population, while the CE/ME 2010 comparison only included CE and ME students, which is a subset of the experimental population.

During Spring 2018, there were four sections of PHYS 2100. Because there was no formal coordination of the course between the three different instructors, we examined only two sections, both of which were taught by the same instructor. One of these sections enrolled the 33 FYrE students along with 48 non-FYrE students. As depicted in Figure 3(a), the median FYrE student earned a grade of $2.0(\mathrm{C})$, while the median non-FYrE student earned a $1.0(\mathrm{D})$. Moreover, the passing rate (i.e., percentage of students earning $\mathrm{C}$ or higher) of FYrE students was $59 \%$ vs. $29 \%$.

During Spring 2019, there were again four sections of PHYS 2100. This time the physics department instituted some formal coordination between the four instructors of the course, although the only completely common elements of the course were the syllabi and schedule of topics. In speaking to the instructors, two of them additionally coordinated their exam content and grading schemes. (These instructors did not have any FYrE students in their sections.) With more norming taking place around course grades, the grades themselves were significantly higher. Nonetheless, the results were similar to Spring 2018 in that the FYrE students performed better with a median grade of 3.0 (B) vs. $2.3(\mathrm{C}+$ ), as shown in Figure 3(b). Because the GPAs as a whole were higher, the difference in passing rate became smaller, with $89 \%$ for FYrE vs. $86 \%$ for Non-FYrE.

Aside from the FYrE students' better performance, the strongest conclusions we can derive from these data is that absolute course grades are not necessarily a reliable indicator of mastery, particularly when the logistics of the course vary from year to year, when the course sections are taught by non-tenure-line faculty, and when there is little discussion or development of grading methods, laboratory instruction, or normalization of grading across sections. 
Spring 2018 PHYS 2100 Course Grades

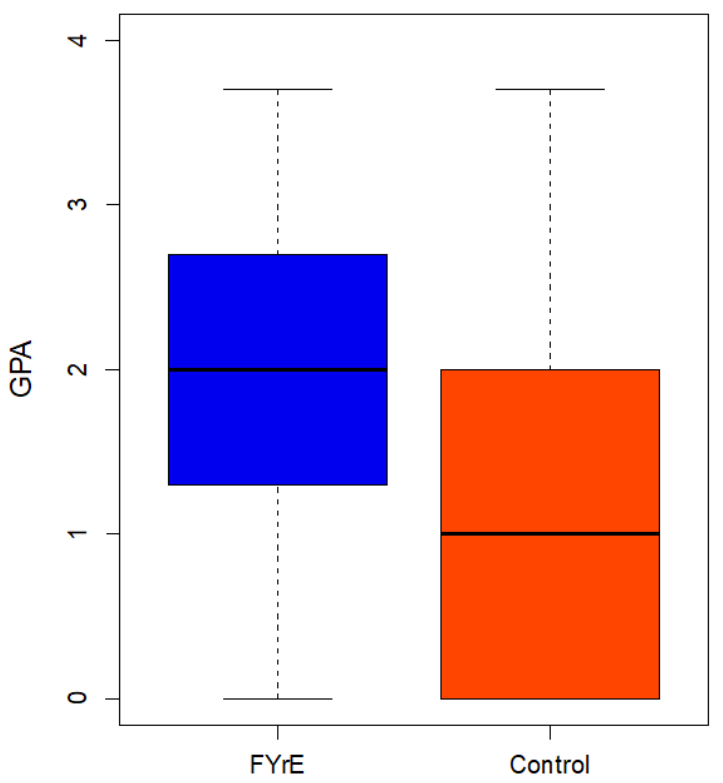

(a)
Spring 2019 PHYS 2100 Course Grades

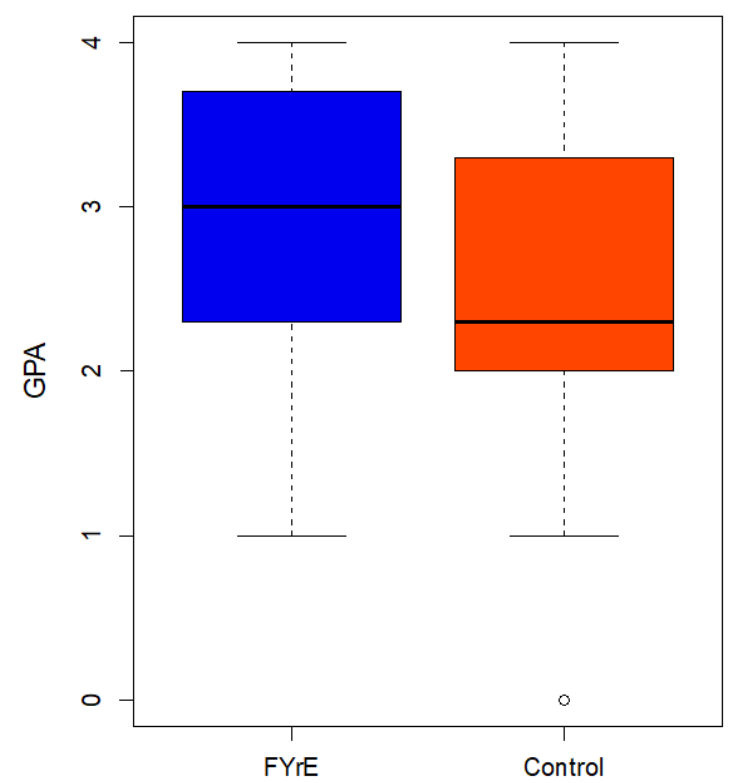

(b)

Figure 3. Physics course grades in (a) 2018 and (b) 2019 for FYrE and Control (Non-FYrE) groups.

The FCI exam provides a complementary measurement of students' mastery that does not have as much dependence on the specifics of the course situation (e.g., grading policy, instructor, etc.). In particular, this assessment targets students' understanding of the basic concepts of force and motion that are considered essential for students to master Newtonian mechanics. These concepts are presented within the first 5-6 weeks of PHYS 2100 by all instructors. Therefore, all things being approximately equal, we would expect to see relatively consistent results from year to year on this assessment.

In Spring 2018, we administered the FCI exam to all PHYS 2100 students during the first and last weeks of the course. These times are denoted "pre-2100" and "post-2100", respectively, in Figure 4. The tested population included both FYRE and Non-FYRE students from ECST, as well as other majors, transfer students, and students taking the course a second time after failing once. FYrE students took the course immediately after ENGR 1540 and presumably began PHYS 2100 with more knowledge of these concepts than the non-FYrE students (median pre2100 score: $37 \%$ vs. $27 \%$ ). At the end of PHYS 2100, all of the students made (small) gains, but the FYrE students outperformed the non-FYrE students (median post-2100 score: 45\% vs. 33\%). 
Spring 2018 FCI Exam Results

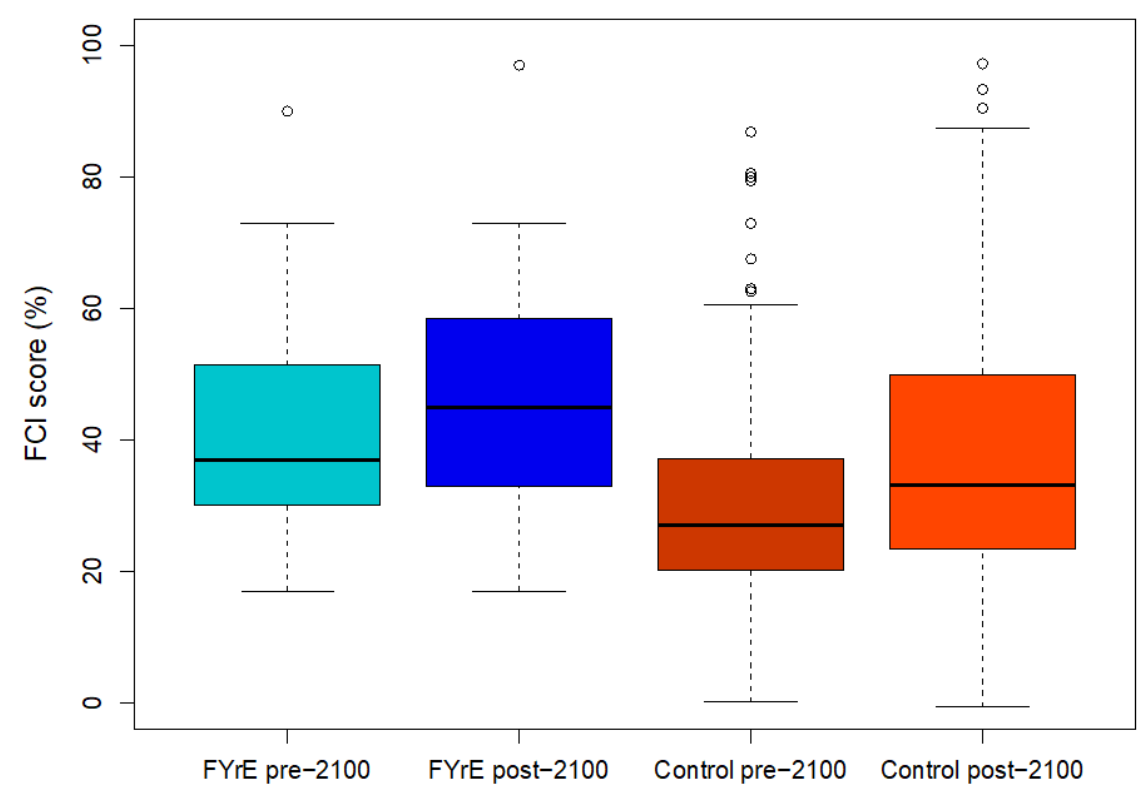

Figure 4. FCI Exam Results in Spring 2018 for FYrE and Control (Non-FYrE) groups.

One possible criticism of this analysis is that it may be possible that the FYrE students entered Cal State LA with more physics knowledge than their non-FYrE peers. Although admission requires at least two years of laboratory sciences, physics is not specifically required, and we did not examine if students in this study had taken physics in high school. Therefore, during the 2018-19 academic year, we administered the FCI to the FYrE students during the first week of ENGR 1540 course in Fall 2018 (denoted "FYrE pre-IM"), along with the usual pre- and postcourse exams for PHYS 2100 in Spring 2019. This enabled us to assess the physics knowledge of FYrE students when they enter Cal State LA and also how much they gained from ENGR 1540. It should be noted that more than a month passes between the end of ENGR 1540 and the beginning of PHYS 2100 due to winter break.

We found that the median FCI score of FYrE students before they begin ENGR 1540 is identical to non-FYrE students before they begin PHYS 2100 (27\% vs. 27\%). As can be seen in Figure 5, even the distributions of scores are quite similar. This suggests that the FYrE students are not entering Cal State LA with superior physics knowledge to their non-FYrE counterparts. As in Spring 2018, the FYrE students began PHYS 2100 with noticeably higher scores (median: 40\%) than the non-FYrE students. At the end of PHYS 2100, the median FYrE score was again higher than the median non-FYrE score (57\% vs. 40\%). Again, the post- 2100 scores of the non-FYrE students are similar to the pre-2100 scores of the FYrE students, with identical medians.

Together these data suggest that the median FYrE student began PHYS 2100 with approximately the same conceptual knowledge as the median non-FYrE student at the end of PHYS 2100. 
These data also suggest being introduced to the concepts of physics before PHYS 2100 is beneficial for our students.

\section{Spring 2019 FCI Exam Results}

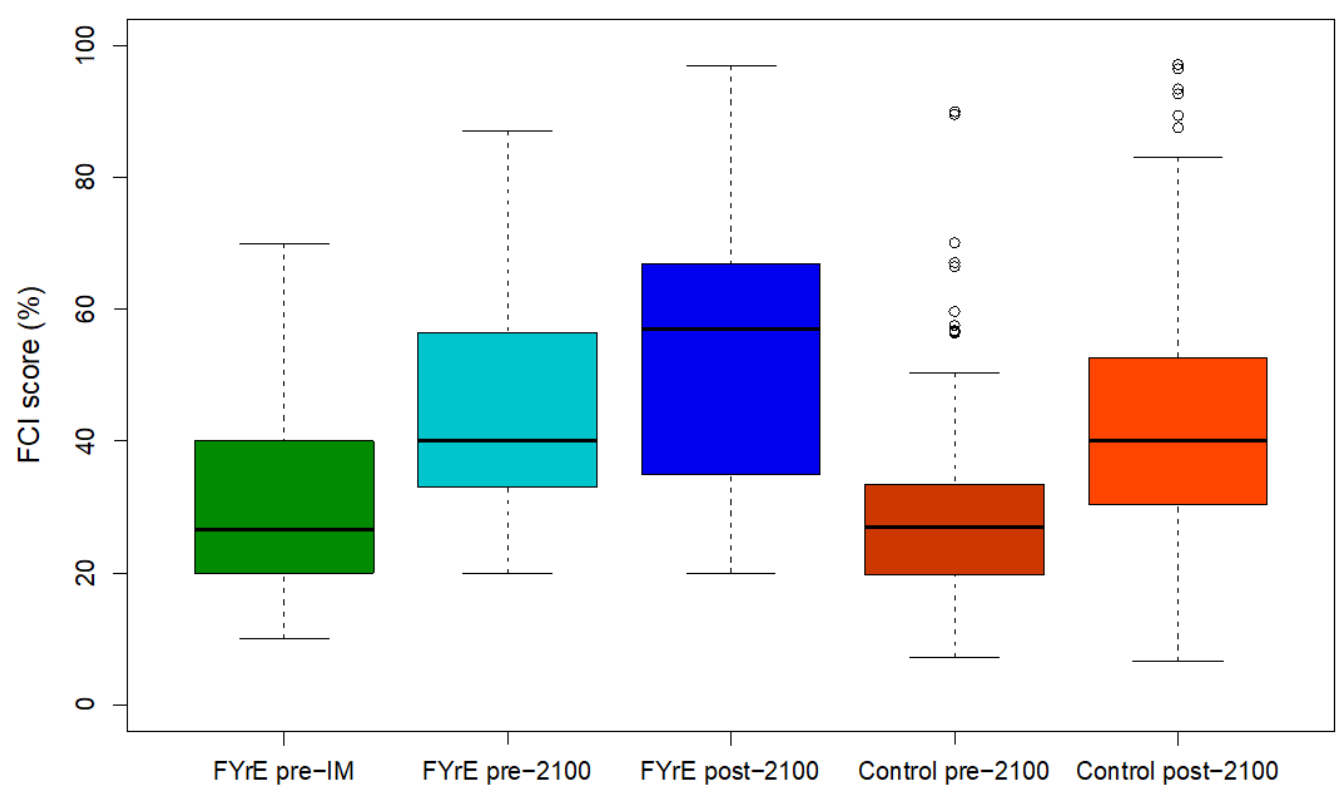

Figure 5. FCI Exam Results in Spring 2019 for FYrE and Control (Non-FYrE) groups.

While the analyses above are encouraging, we note that the designers of the FCI designate a score of $60 \%$ as the threshold for entry-level understanding of Newtonian mechanics. ${ }^{[14]}$ Evaluated by this metric, in Spring 2018, only $25 \%$ of FYrE students and $17 \%$ of non-FYrE students were able to achieve entry-level understanding or better after completing PHYS 2100. In Spring 2019, the results were somewhat more favorable for FYrE students with $34 \%$ of them earning $\geq 60 \%$ on the FCI, while again only $17 \%$ of non-FYrE students were able to earn the same.

Another way of expressing the change in conceptual knowledge over the duration of the course is to compute the normalized gain associated with the pre- and post-2100 FCI exam scores. The normalized gain is computed using equation (1): ${ }^{[15]}$

$$
\text { norm.gain }=\frac{F C I_{\text {post }}-F C I_{\text {pre }}}{100 \%-F C I_{\text {pre }}}
$$

Using this definition, we found that the median normalized gains for both types of students were approximately 0.10 (or $10 \%$ of the maximum possible gain on the exam) in Spring 2018, shown in Figure 6(a). For comparison, in Spring 2019, the median normalized gains were between 0.16-0.19, Figure 6(b). We also computed the normalized gain for the FYrE students between their pre-2100 and pre-IM scores ("post-IM") and found that the median normalized gain was 0.25 . From these data we can conclude that both the FYrE and non-FYrE students appear to gain 
similar amounts of conceptual knowledge from a single semester of physics, be it ENGR 1540 or PHYS 2100. Interestingly, however, the FYrE students continue to gain knowledge by seeing the same concepts a second time in PHYS 2100.

Spring 2018 FCl Exam Gains

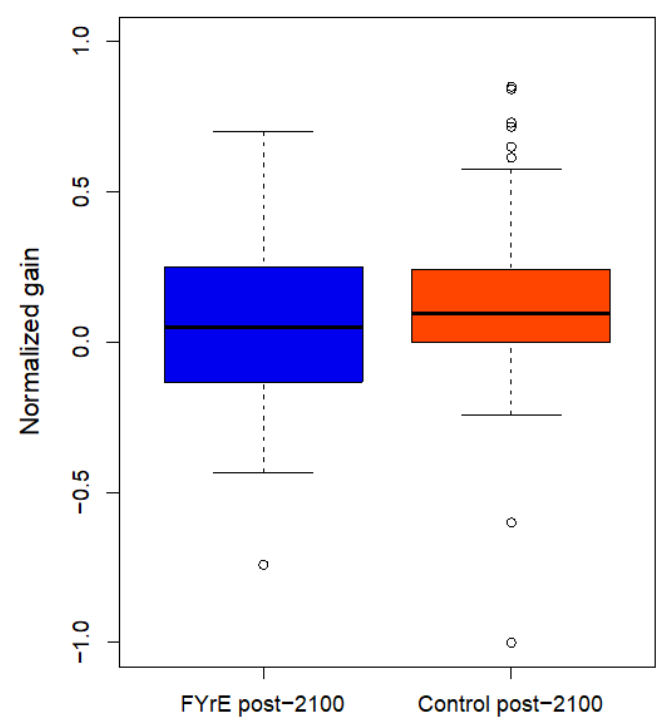

(a)

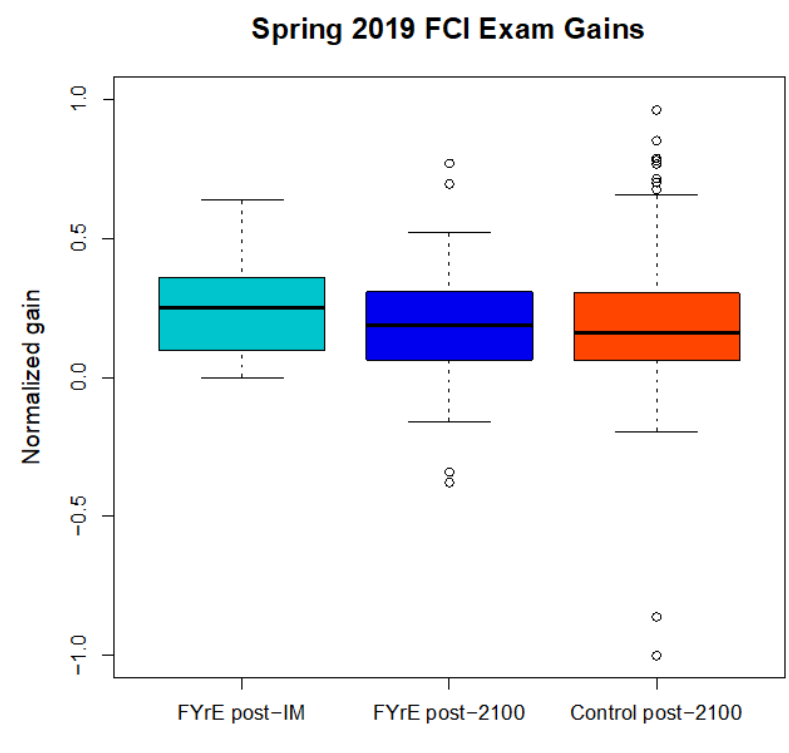

(b)

Figure 6. FCI exam gains in (a) 2018 and (b) 2019 for FYrE and Control (Non-FYrE) groups.

To put the normalized gain numbers into context, a recent secondary analysis ${ }^{[16]}$ of FCI results found that the average normalized gain on the FCI was 0.22 if traditional lecture formats are used for the introductory physics course. When "interactive engagement" techniques are used, the average normalized gain is 0.39 . The authors of this study found that these averages are quite consistent across different types of colleges and universities. We note, however, that there is a relative lack of published FCI exam data from colleges/universities serving predominately Hispanic and/or first-generation college student populations. Nonetheless, the PHYS 2100 gains we have observed are encouraging. Given the extensive use of active learning techniques in ENGR 1540, we might expect the post-IM gain of the FYrE students to be higher, but we note that we have not administered the FCI exam to them at the end of ENGR 1540. Instead, the next time that these students take the FCI exam is at the beginning of PHYS 2100 (along with the non-FYrE students). There is a six-week gap between the final week of ENGR 1540 and the first week of PHYS 2100, and therefore it is probable that some of the gains from ENGR 1540 are lost during this intervening time. This could potentially be addressed in the future by administering the exam to FYrE students at the end of the ENGR 1540, but this increases the chances of the FCI becoming an ineffective assessment tool for these students due to survey fatigue.

Finally, we compared the pre-ENGR 1540 and pre-PHYS 2100 scores for our current cohort of students (2019-20) to those of last year's cohort (2018-19) in Figure 7. These data demonstrate 
that our students' performance on the FCI prior to taking any physics course at the university (either ENGR 1540 or PHYS 2100) is quite consistent from year to year. In particular, the median pre-ENGR 1540 scores for FYrE students and median pre-PHYS 2100 scores for nonFYrE students are in a narrow range of 23-27\%. Likewise, in both academic years, the median pre-PHYS 2100 scores for the FYrE students are between $37-40 \%$. We also compared the median normalized gain for the FYrE students due to ENGR 1540 and found that it actually decreased slightly between the two cohorts -0.17 in $2019-20$ vs. 0.25 in $2018-19$ - despite the implementation of the aforementioned "6-day cycle" in ENGR 1540 this year.

AY18-19 and AY19-20 FCI Exam Results

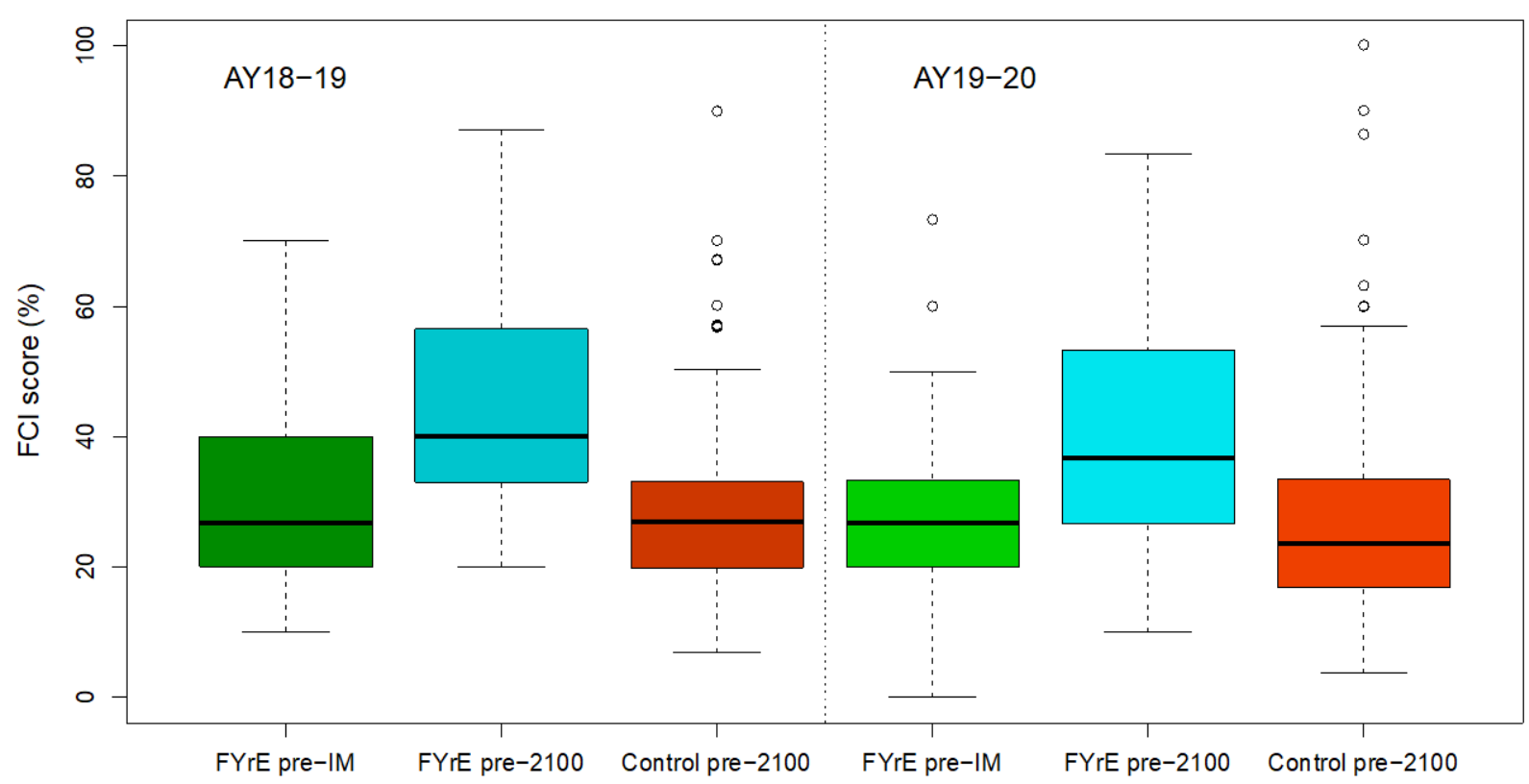

Figure 7: FCI exam results (scores) for both FYrE and non-FYrE groups across two academic years: 2018-19 and 2019-20.

Beyond their performance in introductory physics, we also examined how the FYrE students performed in the statics course (CE/ME 2010) that they take the semester after they pass PHYS 2100. In this case, we have data for two cohorts of the FYrE students who participated in the program before ENGR 1540 was established, and for two cohorts who have taken ENGR 1540. An examination of these data reveals that FYrE students from both sets of cohorts do modestly better than non-FYrE students in terms of GPA in Statics. In particular, the median grade for FYrE students who took ENGR 1540 is B- (vs. C+ for the other groups). The passing rate of FYrE students is also higher (83\% and $84 \%$ for the two FYrE groups) than that of non-FYrE students (66\%), but we observe no significant difference between the FYrE students who have 
taken ENGR 1540 and those who have not. Given our observations of PHYS 2100 course grades, the use of a complementary assessment tool, such as the Concept Assessment Tool for Statics (CATS), ${ }^{[17]}$ might be useful in providing a measure of gains that remains stable from semester to semester, etc.

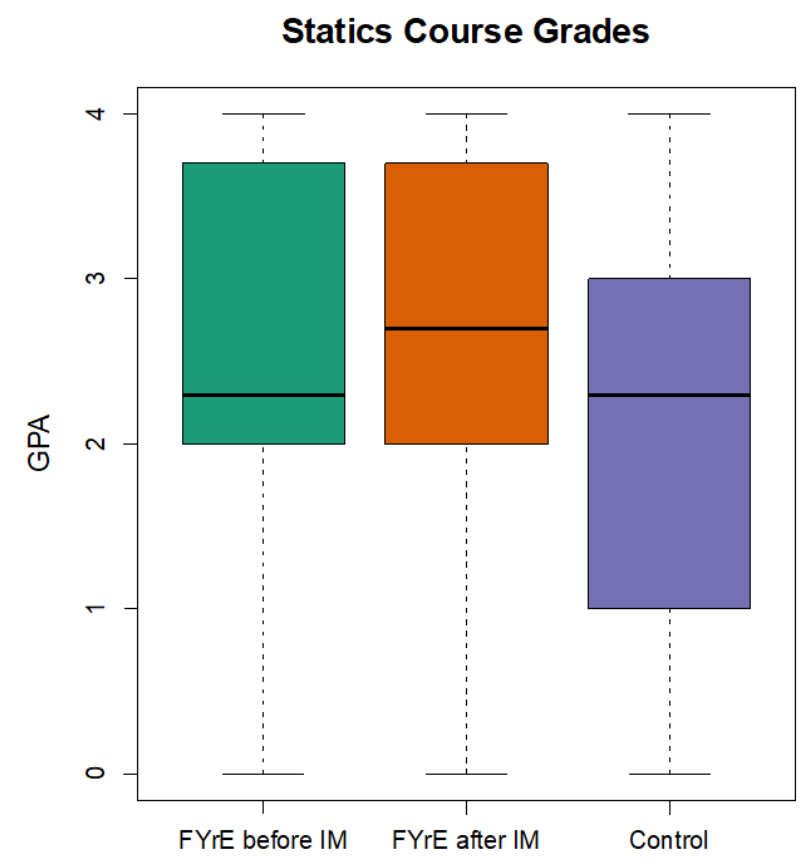

Figure 8. Statics grades for FYrE students (before and after implementation of Introduction to Mechanics Course) and Control (Non-FYrE) Students

\section{Conclusion}

We developed a new Introduction to Mechanics preparatory course to help our students succeed in the Physics I (Mechanics) course, which traditionally has had a very low passing rate. Our underlying assumption is that our students need to build a foundation in both multi-step problem solving and basic concepts in physics before matriculating on to the regular introductory physics course. As such, Introduction to Mechanics focuses on helping students develop an in-depth understanding of key concepts of Physics I. The course uses a 6-day learning cycle (pre-class assignment $\rightarrow$ class $\rightarrow$ homework $\rightarrow$ homework self-reflection) that is based on the assumption that students need to see a concept at least 4 times over a period of 7 days to assimilate the knowledge, as proposed by Ebbinghaus' memory research.

Effectiveness of the new course was assessed by comparing Physics I grades and passing rates, scores in the force concept inventory (FCI) and Statics grades and passing rates. Performance of students in the study are consistently better across all assessment instruments when compared to 
other students. However, results also show a lot of room for improvement, since many students continue to fall behind the minimum threshold of $60 \%$.

It is without a doubt that added time on task plays a role in students' improvement in physics. However, we believe that time on task is not the main factor here, since control groups do spend 7 hours a week in lecture, lab and a tutorial workshop, which is a considerable amount of time and do not perform as well. The effect of repeated "exposure" may also play a role, but considering that most repeating students' performance is not significantly better, we believe the focus on in-depth understanding of the course is the key factor in the success of the course. Finally, it is also important to highlight that the students in the study also benefit from other interventions, such as block scheduling (stronger community), supplemental instruction workshops and peer mentoring. Nevertheless, prior to the introduction of ENGR1540 to the program, these interventions alone did not result in a better performance in physics, even though they have other positive impacts on students.

\section{Acknowledgements}

This work is currently supported by the National Science Foundation (DUE-1727054). Any opinions, findings, and conclusions or recommendations expressed in this material are those of the authors and do not necessarily reflect the views of the National Science Foundation. 


\section{References}

${ }^{[1]}$ Menezes, G. B., \& Won, D., \& Tufenkjian, M., \& Allen, E. L., \& Schiorring, E. (2017, June), An Integrated First-Year Experience at ECST (FYrE@ECST) Paper presented at 2017 ASEE Annual Conference \& Exposition, Columbus, Ohio. https://peer.asee.org/27573

${ }^{[2]}$ Menezes, G. B., \& Allen, E. L., \& Ragusa, G., \& Schiorring, E., \& Nerenberg, P. S. (2019, June), Board 106: Quantitative and Qualitative Assessment of Large-scale Interventions in a First-year Experience Program Paper presented at 2019 ASEE Annual Conference \& Exposition , Tampa, Florida. https://peer.asee.org/32177

${ }^{[3]}$ Kornblum, S. L., \& Avery El, Z. K., \& Menezes, G. B., \& Won, D., \& Allen, E. L. (2017, August), Enhancing Engineering First-Year Experience (FYrE) through Supplemental Instruction Paper presented at 2017 FYEE Conference, Daytona Beach, Florida. https://peer.asee.org/29408

${ }^{[4]}$ Sun, C., \& Won, D., \& Allen, E. L., \& Gadhia, H. (2016, June), Golden Eagle Flight Plan Online: A Web-Based Advisement Tool to Facilitate Developmental Advising Paper presented at 2016 ASEE Annual Conference \& Exposition, New Orleans, Louisiana. 10.18260/p.25411

[5 ] IUSE:The First-Year Experience at ECST," DUE-\#1727054.

${ }^{[6]}$ N. Li, G.B. Menezes, P. Nerenberg, E. Allen, "First-Year Experience (FYrE@ECST): Intro to Physics Course (WIP)", 2018 The Collaborative Network for Engineering and Computing Diversity (CoNECD), Crystal City, VA, 2018.

${ }^{[7]}$ Cutri, R., \& Marim, L. R., \& Cordeiro, J. R., \& Gil, H. A. C., \& Guerald, C. C. T. (2016, June), Kahoot, A New and Cheap Way to Get Classroom-Response Instead of Using Clickers Paper presented at 2016 ASEE Annual Conference \& Exposition, New Orleans, Louisiana. $10.18260 / \mathrm{p} .25512$

${ }^{[8]}$ Ebbinghaus H (1885) Über das Gedächtnis. Leipzig: Dunker.

${ }^{[9]}$ Murre JMJ, Dros J (2015) Replication and Analysis of Ebbinghaus' Forgetting Curve. PLoS ONE 10(7): e0120644. https://doi.org/10.1371/journal.pone.0120644

${ }^{[10]}$ Bloom, B. S. (1956). "Taxonomy of Educational Objectives, Handbook I: The Cognitive Domain." New York: David McKay Co Inc.

${ }^{[11]}$ N. Li, N. Water-Perez, H. Shen, “A Self-Assessment Based Homework Model”, Proceedings of 2019 PSW Conference.

${ }^{[12]}$ D Hestenes, M Wells, and G Swackhamer. "Force concept inventory." The Physics Teacher 1992; 30:141-158.

${ }^{[13]}$ Sands, David; Parker, Mark; Hedgeland, Holly; Jordan, Sally and Galloway, Ross (2018). Using Concept Inventories to Measure Understanding. Higher Education Pedagogies, 3(1) pp. $173-182$.

[14] D Hestenes and I Halloun. "Interpreting the force concept inventory: A response to March 1995 critique by Huffman and Heller." The Physics Teacher 1995; 33:502-506.

${ }^{[15]}$ RR Hake. "Interactive-engagement versus traditional methods: A six-thousand-student survey of mechanics test data for introductory physics courses." American Journal of Physics 1998; 66:64-74.

[16] J Von Korffa, B Archibeque, KA Gomez, T Heckendorf, SB McKagan, EC Sayre, EW Schenk, C Shepherd, and L Sorrell. "Secondary analysis of teaching methods in introductory physics: A 50 k-student study.” American Journal of Physics 2016; 84:969-974. 
[17] PS Steif and JA Dantzler. "A Statics Concept Inventory: Development and Psychometric Analysis." Journal of Engineering Education 2005; 33:363-371. 